\title{
GLOMERULOPATIA MEMBRANOSA REVERSÍVEL ASSOCIADA AO USO DE ANTI-INFLAMATÓRIO NÃO ESTERÓIDE
}

Nicole Kraemer Redeker ${ }^{1}$, Marina Demiquei Cobalchini ${ }^{1}$, Paola Fonseca Minuzzi ${ }^{1}$, Mateus Martins Nudelmann ${ }^{1}$, Marina Magagnin

Naspolini ${ }^{1}$, Jayme Eduardo Burmeister ${ }^{2}$

${ }^{1}$ Acadêmicos de Medicina da Universidade Luterana do Brasil

2 Professor do curso de Medicina da Universidade Luterana do Brasil

\section{Resumo}

INTRODUÇÃO: A glomerulopatia membranosa é caracterizada por lesão da membrana basal glomerular e apresenta-se clinicamente como síndrome nefrótica. Glomerulopatia membranosa por uso abusivo de antiinflamatórios não esteroides (AINEs) é uma condição rara, apesar dos (AINEs) estarem entre as drogas mais prescritas no mundo. Estes podem induzir alterações deletérias na função renal, principalmente em pacientes que os utilizam cronicamente, por atuarem bloqueando as prostaglandinas, responsáveis por manter o fluxo renal. As desordens renais relacionadas ao uso de (AINEs) são por ordem decrescente de frequência: distúrbios hidroeletrolíticos, insuficiência renal aguda, síndrome nefrótica, necrose papilar e outras. MÉTODOS: Foram coletados dados de anamnese e de prontuário de um paciente, previamente internado, em acompanhamento no ambulatório de nefrologia do Hospital Universitário da ULBRA por glomerulopatia membranosa. RESULTADO: Homem, 66 anos, foi internado no Hospital Universitário Ulbra Mãe de Deus no dia 07/05/2015 para investigação de quadro clínico de edema importante e simétrico de membros inferiores. Tinha história de hipertensão arterial há 15 anos. Fazia uso contínuo de hidralazina 50mg 4x/dia, furosemida 40mg 1x/dia e enalapril 20mg 2x/dia. Relatou fazer uso crônico de diclofenaco (AINE) para dores na coluna há 2 anos. Exames laboratoriais de 14/05/2015 evidenciaram: proteinúria nefrótica (18609 mg/24h); hipoalbuminemia (albumina: 1,0 g/dL); creatinina 1,31 mg/dL; hipotireoidismo (TSH 19). 
Foi indicada realização de biópsia renal. O diagnóstico anatomopatológico foi de glomerulonefrite membranosa, condizente com síndrome nefrótica. Paciente foi orientado a suspender o uso do diclofenaco. Exames laboratoriais de 27/08/2015: albumina 3,9 g/dL; proteína, urina em amostra $14 \mathrm{mg} / \mathrm{dL}$; creatinina plasmática $0,98 \mathrm{mg} / \mathrm{dL}$; relação proteinúria/creatininúria 0,16 . Percebeu-se, assim, que após a interrupção do uso de AINE houve uma remissão completa da síndrome nefrótica CONCLUSÃO: Pacientes com síndrome nefrótica e cuja biópsia renal evidencie glomerulopatia membranosa sem outra etiologia plausível devem ser avaliados sobre o possível uso de (AINE). A presença de nefropatia membranosa concomitante ao uso prévio e persistente de (AINE), na ausência de outra etiologia possível e acompanhada da reversibilidade da proteinúria patológica após a retirada do uso da droga, caracterizam esta associação etiológica.

Palavras Chave: glomerulopatia, nefropatia, anti-inflamatório 